\title{
EXPERIMENTAL VS. THEORETICAL DESIGN APPROACHES FOR THIN-WALLED COLD-FORMED STEEL BEAM-COLUMNS
}

\author{
Nadia Baldassino ${ }^{1}$, Claudio Bernuzzi² and Marco Simoncelli ${ }^{2, *}$ \\ ${ }^{1}$ Department of Civil, Environmental and Mechanical Engineering, University of Trento, Trento, Italy \\ ${ }^{2}$ Department of Architecture, Built Environment and Construction Engineering, Politecnico di Milano, Milano, Italy \\ *(Corresponding author: E-mail: marco.simoncelli@polimi.it)
}

\section{A B S T RACT}

The response of thin-walled cold-formed (TWCF) members is significantly influenced by local and distortional buckling phenomena as well as by their interactions with overall instability. Furthermore, because of the frequent use of monosymmetric cross-section members, their design is often complex and laborious engineering calculations are required, independently of the adopted provisions. With reference to the European (EU) and United States (US) design standards, which are the most commonly adopted worldwide, different alternatives can currently be used: a direct comparison between the predicted load carrying capacities should hence be of great interest for structural engineers and manufacturing technicians. This issue is discussed in the paper, which is focused on isolated TWCF beam-columns. In particular, 5 EU and 2 US alternatives have been discussed focusing attention on the pure theoretical approaches to evaluate the member performance. The applicative part proposes a direct comparison between the associated axial force bending-moment domains investigating the influence of the member slenderness as well as of the moment distribution. Furthermore, these alternatives have been applied to predict the strength of members tested in laboratory for which the behavior of an adequate number of nominally identical specimens has been thoroughly investigated. The proposed statistical re-elaboration of test data, which is comprised of 8 practical cases differing for cross-section sizes, materials and length, for a total of 112 compression tests, allows for defining the experimental design performance to be directly compared with the corresponding one associated with the considered design approaches.

\section{A R T I C LE H IST O RY}

\begin{tabular}{|c|c|}
\hline Received: & 03 October 2017 \\
\hline Revised: & 20 December 2017 \\
\hline Accepted: & 23 December 2017 \\
\hline
\end{tabular}

\section{K E Y W O R D S}

Thin-walled cold-formed

(TWCF) members;

Effective geometric properties;

Beam-column design domains;

Experimental compression tests;

Design approach accuracy

Copyright $\odot 2019$ by The Hong Kong Institute of Steel Construction. All rights reserved.

\section{Introduction}

The use of thin-walled cold-formed (TWCF) members has recently increased throughout the more industrialized Countries for a great amount of applications [1-3] because it offers an efficient load capacity-to-weight ratio, associated with a great economy in production, transportation and handling. As a consequence, labor cost and worker fatigue are significantly reduced by guaranteeing, at the same time, great flexibility in design, high productivity and competitive levels of product standardization. Owing to these advantages, more slender and complex TWCF cross-section types (Fig. 1) are nowadays proposed to the market, which exacerbate the influence of local, distortional and global buckling phenomena and their interaction on the performance of the profiles [47]. In addition to a complete lightweight structural solution for residential buildings (Fig. 2), these elements are also frequently and conveniently employed as purlins and supports of roofs, cladding systems and partitions in the case of the more conventional civil and industrial steel buildings with skeleton frames made of hot-rolled profiles.
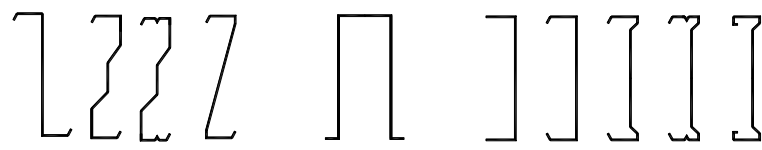

Single open sections

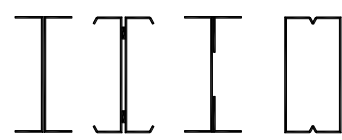

Built-up sections

Fig. 1 Typical TWCF cross-sections

As a result of the rapid world globalization and of the quite modest transportation costs, in recent years design, fabrication and erection sites of a growing number of TWCF solutions are often separated by few thousands of kilometers. Therefore, a general overview of the design procedures adopted by different countries should be of great interest for researchers and designers.

A recent study on conventional moment-resisting frames made of hotrolled members [8,9] demonstrated non-negligible discrepancies among the predicted design alternatives allowed by the European (EU) [10] and United States (US) [11] provisions. In this paper, the attention is focused on isolated
TWCF members and on the most common design approaches adopted in Europe and USA. In total, seven different alternatives, 5 related to the EU and 2 to the US design practice, are briefly discussed and compared, pointing out similarities and differences. Furthermore, their application is addressed to draw the bending moment-axial load resistance domains of beam-columns by considering different member slenderness and moment distributions. Finally, attention is focused on the prediction of the resistance of members tested under compression and differing for cross-section sizes, steel grade and effective length. The great amount of experimental data (in total 112 tests related to eight different cases) allows for a statistical re-elaboration of test data according to the limit states design philosophy. The experimental design performances so obtained are directly compared with those associated with the considered design approaches to assess their effective reliability for practical design purposes.

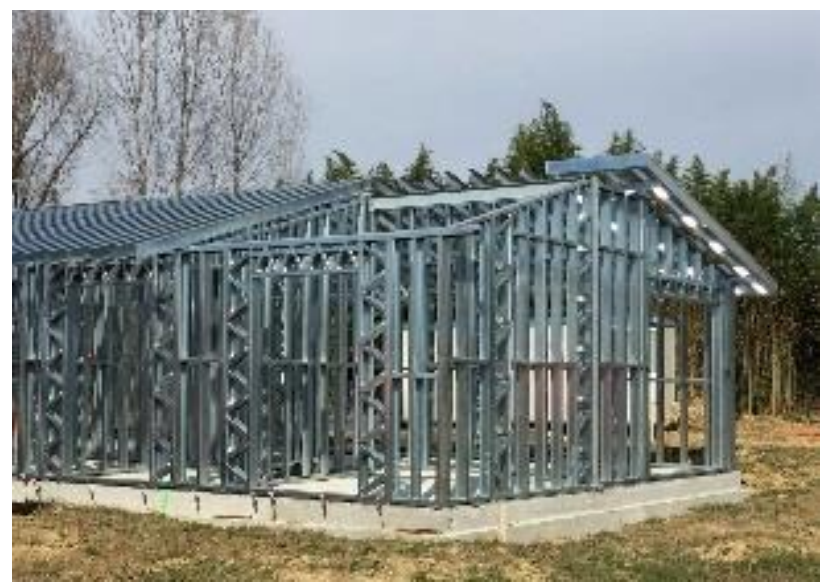

Fig. 2 Typical TWCF steel solution (courtesy of COGI s.r.l.)

\section{On the assessment of the effective geometric properties}

As already mentioned, TWCF member behaviour is significantly affected by buckling phenomena (local, distortional, global and their mutual interactions). From a practical point of view, design is generally based on geometric parameters (e.g. mainly area, section moduli and second moments of area) lower than the ones associated with the gross cross-section and determined 
by means of methods based on the well-known effective width concept $[12,13]$. The generic cross-section is considered composed by sets of internal and outstand (unstiffed) elements, that are indicated as A and B components in Fig. 3 , and suitable rules are proposed by codes of practice to evaluate the parts conventionally considered resisting to compressive stresses when local buckling takes place.

In the case of internal plates, the regions adjacent to the supported edges are considered to be effective in carrying compressive stresses while the ones far from supports are considered completely ineffective in resisting compression (Fig. 4a). Similarly, in case of outstand plates (Fig. 4b), the zone close to the free edge is considered not resisting, i.e. non-effective. This concept was initially introduced by von Karman et al. [14], which defined the effective width, $b_{e}$, as:

$$
b_{e}=\left(\sqrt{\frac{\sigma_{c r}}{f_{y}}}\right) \cdot b
$$

where $b$ is the plate width, $f_{y}$ is the yield stress of the material and $\sigma_{c r}$ represents the critical elastic buckling stress accounting for the restraints and the compressive stress distribution.

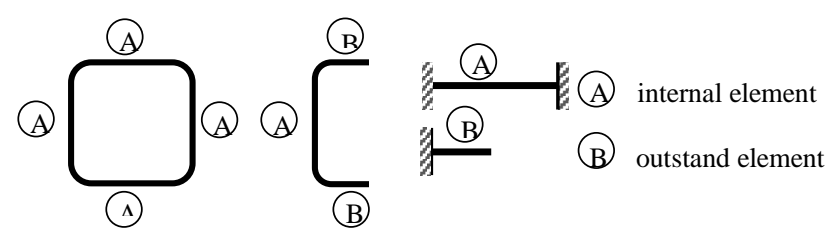

Fig. 3 Typical components of the TWCF cross-sections

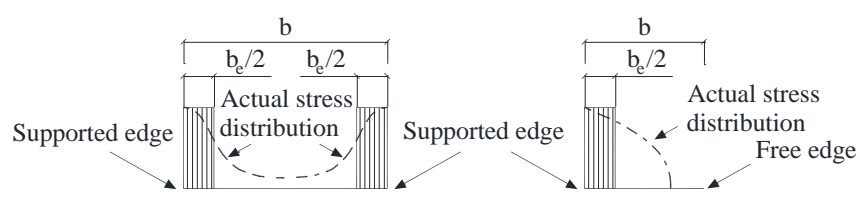

a)

b)

Fig. 4 Effective width for internal (a) and outstand (b) compressed plate

In 1946, Winter [15] improved this expression to also account for the effects of geometrical and mechanical imperfections and proposed to estimate the effective width by accounting for the actual stress distribution, which in case of constant stresses is defined as:

$$
b_{e}=\left[\sqrt{\frac{\sigma_{c r}}{f_{y}}}\left(1-0.22 \cdot \sqrt{\frac{\sigma_{c r}}{f_{y}}}\right)\right] \cdot b \leq b
$$

Recently, the effective width method has been improved to account for the presence of the distortional buckling, also known as "stiffener buckling" or "local-torsional buckling". This mode is characterized by the rotation of the flange at the flange/web junction in members with edge stiffened elements (Fig. 5) and may be directly studied by finite strip analysis, finite element models or, for practical applications, by using the equations proposed by the standard codes for a few cross-section types.

According to Eurocode 3 part 1-3 [16] as well as to the AISI S100 specifications [17], with reference to TWCF mono-symmetric cross-section members, different effective cross-sections (Fig. 6) have to be evaluated to assess the structural performances: one for the axial force $N_{E d}$, one for the bending moment along the symmetry axis $M_{y, E d}$ and two $\left(M_{z, E d+}\right.$ or $\left.M_{z, E d-}\right)$ for bending moment along the non-symmetry axis, to be alternatively used depending on the part under compression.

Design rules for TWCF beam-columns, like the ones for the more conventional hot-rolled members, are based on approaches which combine the resistance of members under axial force with those corresponding to the cases of pure flexure along both principal cross-section axes. Verification checks are developed by using the superposition principle: on the basis of the generalized set of forces arising from the structural analysis output, the effects of $N_{E d}, M_{y, E d}$ and $M_{z, E d}$ are directly added to evaluate the safety index (SI), i.e. the coefficient of utilization ranging from 0 to 1 (achievement of the limit conditions), expressed, in general terms, as:

$S I=S I_{N}\left(N_{E d}\right)+S I_{M y}\left(M_{y, E d}+\Delta M_{y, E d}\right)+S I_{M z}\left(M_{z, E d}+\Delta M_{z, E d}\right) \leq 1$
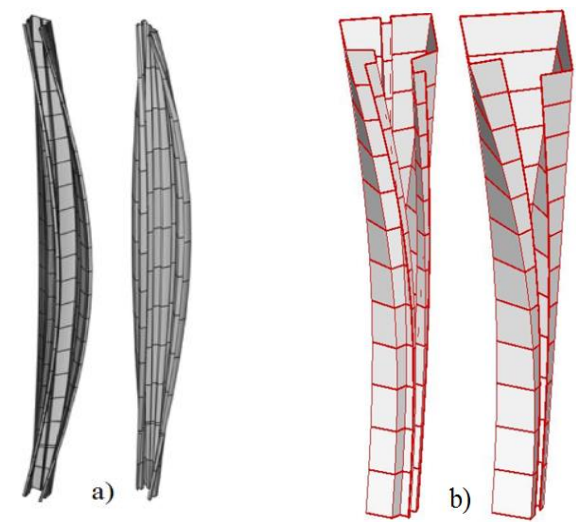

Fig. 5 Typical buckling modes for a compressed simply-supported (a) and cantilever (b) beams (obtained by means of Śiva software, courtesy of prof. A. Gobetti - University of Pavia)

EFFECTIVE CROSS-SECTION

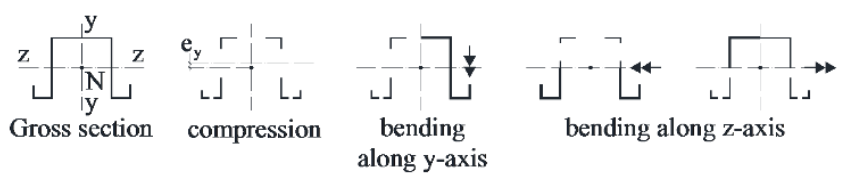

Fig. 6 Effective cross-sections to be considered for the design verification checks

where $\mathrm{SI}_{\mathrm{K}}\left(\mathrm{K}_{\mathrm{Ed}}\right)$ represents the safety index for the generalized $\mathrm{K}$ force, i.e. neglecting the possible interactions with the other design components, and $\Delta \mathrm{M}$ indicates additional secondary bending moments due to the shift between the gross and the effective centroid of the cross-section $\left(e_{y}\right.$ and $\left.e_{z}\right)$, with $\Delta M_{y, E d}=$ $N_{E d} \cdot e_{z}$ and $\Delta M_{z, E d}=N_{E d} \cdot e_{y}$.

It should be noted that TWCF members, because of the cold-forming production process, often present a single axis of symmetry (indicated in the following as y-axis) and hence the non-coincidence between the shear center and the cross-section centroid, the coupling between bending and torsion and the warping torsion could generate an additional state of stress with normal $\left(\sigma_{w}\right)$ and tangential $\left(\tau_{w}\right)$ components. These warping stresses cannot be captured by means of the traditional theory of structures, as already stated few decades ago, when thin-walled beam theory was well-established [18-20] and consequently proposed for routine design. Nevertheless, in all the TWCF design codes, with the sole exception of the Australian provisions for pallet racks [21], the presence of the bi-moment $\left(\mathrm{B}_{\mathrm{Ed}}\right)$ is actually ignored, despite recent studies [22-25] have clearly indicated that also the contribution $\mathrm{SI}_{\mathrm{B}}\left(\mathrm{B}_{\mathrm{Ed}}\right)$ should be necessarily included in eq. 3) to reach the goal of a safe and reliable structural design. Despite the importance of this issue, in the following reference is made to code requirements that are currently in use, hoping in suitable improvements of the design rules in a near future.

\section{Design alternatives for TWCF members}

As previously mentioned, attention is herein focused on members having a single axis of symmetry (y-axis) and hence only the additional contribution $\Delta M_{z, E d}$ has to be considered, since only the shift of the effective geometric crosssection centroid along the $\mathrm{y}$-axis is presented (i.e. $e_{\mathrm{z}}=0$ and hence $\left.\Delta M_{y, E d}=N_{E d} \cdot e z=0\right)$. More in details, making reference to eq. 3), term $\mathrm{SI}_{N}$ depends on the effective cross-section area, $A_{e f f}$, while term $\mathrm{SI}_{M j}$, with $j$ indicating $y$-or $z$-axis, depends on the effective section modulus $W_{\text {eff } j .}$.

\subsection{Design according to the EU alternatives}

As far as design according to European TWCF provisions is concerned, the following alternatives can be considered to assess the member performance:

a) the EC3-1-3 approach (1-3);

b) the EC3-1-1 general method (GEM);

c) the ENV approach (ENV);

d) the EC3-1-1 according to method $A(1-1 A)$;

e) the EC3-1-1 according to method $B(1-1 B)$.

In the following, a brief overview of these methods is presented.

The EC3-1-3 approach. Part 1-3 of Eurocode 3 [16] is the main European reference standard for designing TWCF members. With reference to the buckling verification checks of beam-columns, in section 6.2.5 it is declared 
that "the interaction between axial force and bending moment may be obtained from a second-order analysis of the member as specified in EN 1993-1-1, based on the properties of the effective cross-section". As an alternative, the use of the following interaction formula is allowed:

$\left(\frac{N_{E d}}{N_{b, R d}}\right)^{0.8}+\left(\frac{M_{y, E d}}{M_{b y, R d}}\right)^{0.8} \leq 1$

where $N_{b, R d}$ is the design buckling resistance of a compression member according to the criteria based on the actual buckling mode (i.e. the minimum between flexural, torsional and torsional-flexural buckling load) and $M_{b y, R d}$ is the lateral buckling design strength along the $y$-axis that are defined as:

$$
\begin{aligned}
& N_{\mathrm{b}, \mathrm{Rd}}=\chi_{\min } \frac{A_{e f f} \cdot f_{y}}{\gamma_{M}} \\
& M_{\mathrm{by}, \mathrm{Rd}}=\chi_{L T} \frac{W_{e f f, y} \cdot f_{y}}{\gamma_{M}}
\end{aligned}
$$

where $f_{y}$ is the material yield strength, $\gamma_{M}$ is the material safety factor, $A_{e f f}$ and $W_{\text {eff,y }}$ are the effective area and the effective section modulus, respectively, and the reduction factor $\chi_{\min }$ and $\chi_{L T}$ (indicated, for the sake of simplicity, as $\left.\chi_{\min / L T}\right)$ are given by the expression:

$$
\chi_{\min / L T}=\frac{1}{\varphi_{\min / L T}+\sqrt{\varphi_{\min / L T}^{2}-\bar{\lambda}_{\min / L T}^{2}}} \leq 1
$$

with $\varphi_{\min / L T}$ defined as:

$$
\varphi_{m i n / L T}=0.5 \cdot\left[1+\alpha\left(\bar{\lambda}_{m i n / L T}-0.2\right)+\bar{\lambda}_{\min / L T}^{2}\right]
$$

where $\alpha$ is the imperfection coefficient associated with the stability curve and the relative slenderness $\bar{\lambda}_{\min }$ (pure compression) and $\bar{\lambda}_{L T}$ (only bending moment) are defined as:

$\bar{\lambda}_{\min }=\sqrt{\frac{A_{e f f} \cdot f_{y}}{N_{c r}}}$

$$
\bar{\lambda}_{L T}=\sqrt{\frac{W_{e f f, y} \cdot f_{y}}{M_{c r}}}
$$

where $N_{c r}$ and $M_{c r}$ are the buckling axial load and the elastic critical bending moment for lateral buckling, respectively.

It is worth noting that the use of eq. $4 \mathrm{a}$ ) is limited to the case of mono-axial flexure. By considering the general case of a mono-symmetric cross-section member belonging to a spatial frame, this approach (herein identified as 1-3) can be directly extended to cover the general case of compressive force and biaxial bending moments, defining the associated safety index $\mathrm{SI}_{1-3}^{E U}$ as:

$S I_{l-3}^{E U}=\left(\frac{N_{E d}}{N_{b, R d}}\right)^{0.8}+\left(\frac{M_{y, E d}}{M_{b y, R d}}\right)^{0.8}+\left(\frac{M_{z, E d}+\Delta M_{z, E d}}{M_{z, R d}}\right)^{0.8} \leq 1$

where the flexural resistance along the z-axis, $M_{z, R d}$, is defined as:

$M_{\mathrm{z}, \mathrm{Rd}}=\frac{W_{e f f, z} \cdot f_{y}}{\gamma_{M}}$

The GEM approach. Eurocode 3 in its part 1-1 [10] proposes an innovative design approach [26-28], that is the so-called general method (GEM), appropriate also for structural components having geometrical and loading irregularities and complex support conditions. The overall buckling resistance of the whole skeleton frame is guaranteed when:

$S I_{G E M}^{E U}=\frac{\gamma_{M}}{\chi_{o p} \alpha_{u l t}} \leq 1$ where $\alpha_{u l t}$ is the minimum load multiplier evaluated with regards to the resistance of the most highly stressed cross-section, $\chi_{o p}$ is the buckling reduction factor referred to the overall structural system and $\gamma_{M}$ is the material safety factor.

Ultimate load multiplier for resistance, $\alpha_{u l t}$ is determined as:

$\frac{1}{\alpha_{u l t}}=\frac{N_{E d}}{N_{R}}+\frac{M_{y, E d}}{M_{y, R}}+\frac{M_{z, E d}+\Delta M_{z, E d}}{M_{z, R}}$

where $N_{R}$ is the squash load and $M_{y, R}$ and $M_{z, R}$ are the resistance moments evaluated with reference to the effective cross-section and neglecting the presence of the material safety factor $\gamma_{M}$.

Term $\chi_{o p}$ is the reduction factor to be evaluated by using eqs. 6a) and $6 \mathrm{~b}$ ) that depends on the relative overall slenderness $\bar{\lambda}_{o p}$ defined as:

$\bar{\lambda}_{o p}=\sqrt{\frac{\alpha_{u l t}}{\alpha_{c r, o p}}}$

where $\alpha_{c r, o p}$ is the critical elastic buckling load multiplier.

The ENV approach. The previous ENV version of EC3 [29] proposed an approach to verify beam-column (herein identified as ENV approach) that has been removed from the updated EN version [10] but it is still contained in the EN 15512 [30], that is the European design standard for pallet rack design. In particular, once the effective member capacity for compression force $\left(N_{b, R d}\right.$ from eq. 5a) and for bending moments ( $M_{b y, R d}$ from eq. $\left.5 \mathrm{~b}\right)$ and $M_{z, R d}$ from eq. $5 \mathrm{c}$ ) are defined, the associated safety index $S I_{E N V}^{E U}$ has to meet the condition:

$S I_{E N V}^{E U}=\frac{N_{E d}}{N_{\mathrm{b}, \mathrm{Rd}}}+k_{L T} \frac{M_{y, E d}}{M_{\mathrm{by}, \mathrm{Rd}}}+k_{z} \frac{M_{z, E d}+\Delta M_{z, E d}}{M_{\mathrm{z}, \mathrm{Rd}}} \leq 1$

where $k_{L T}$ and $k_{z}$ are suitable moment coefficients depending on the slenderness of the member as well as on the distribution of the bending moments along the member.

The EC3-1-1 approaches according to the A and B methods. As already mentioned, European TWCF design provisions, i.e. part 1-3 of the EC3 states that also part 1-1 [10] could be considered for member verification checks as an alternative to eqs. 3), even though the flexural-torsional buckling mode for compressed members is ignored because in the general part of EC3 attention is paid only to bi-symmetric cross-section members. The extension of this approach to members with a sole axis of symmetry is suggested by the upcoming version of the European rack design code [31], which is now in the phase of public enquiry. With reference to this extension proposal, which is of course of great interest providing practical indications to apply also the approach proposed in EC3 part 1-1 to mono-symmetric cross-section members, beam-columns have to satisfy the following conditions:

$\frac{N_{E d}}{N_{b, R d}}+k_{y y} \frac{M_{y, E d}}{M_{b y, R d}}+k_{y z} \frac{M_{z, E d}+\Delta M_{z, E d}}{M_{z, R d}} \leq 1$

$\frac{N_{E d}}{\chi_{z} \frac{A_{e f f} \cdot f_{y}}{\gamma_{M I}}}+k_{z y} \frac{M_{y, E d}}{M_{b y, R d}}+k_{z z} \frac{M_{z, E d}+\Delta M_{z, E d}}{M_{z, R d}} \leq 1$

where $\chi_{z}$ is the reduction factors due to flexural buckling along the nonsymmetry $(\mathrm{z})$ axis.

The interaction factors $k_{y y}, k_{y z}, k_{z y}$ and $k_{z z}$ depend on the approach, which can be selected from two alternatives: method 1 (1-1A) and method 2 (1-1B), which are addressed in Annex A and Annex B of EN 1993-1-1, respectively. As to the use of these methods, the prEN pallet rack design provisions suggest only the 1-1B approach. Furthermore, it is worth underlining, as clearly stated by Boissonade et al. [32], that the 1-1B formulation, proposed by Austrian and German researchers, is generally less complex, quicker and simpler than the 1 $1 \mathrm{~A}$ developed by a team of French and Belgian researchers. Once the approach (i.e. the method A or B) to assess the $k_{j k}$ coefficients is selected, the associated safety index, i.e. $S I_{1-1 A}^{E U}$ or $S I_{1-1 B}^{E U}$, is defined as the maximum value from those deriving from eqs. $11 \mathrm{a}$ ) and $11 \mathrm{~b}$ ). 


\subsection{Design according to the US approaches}

Two approaches can be considered for which concerns the US design coldformed design code [17], that are identified in the following as the effective width method (EWM) and the direct strength method (DSM).

The EWM approach. The first approach proposed by US design provisions for TWCF members, deriving directly by the Winter studies, is the effective width method $(E W M)$. Like the EU alternatives previously presented, the evaluation of the effective cross-section properties under compression and bending is required. Accounting for the different US symbols to identify the cross-section principal axes, i.e. $x$ and $y$ instead of $y$ and $z$, respectively, on the basis of the values of the design axial load (P, corresponding to $N_{E d}$ according to EU notation) and bending moments $M_{x}$ and $M_{y}$ (corresponding to $M_{y, E d}$ and $M_{z, E d}$, respectively), it is required that:

$$
S I_{E W M}^{U S}=\frac{P}{0.9 \cdot P_{n}}+\frac{M_{x}}{0.9 \cdot M_{n x}}+\frac{M_{y}}{0.9 \cdot M_{n y}} \leq 1
$$

where $P_{n}$ is the nominal compression member capacity and $M_{n x}$ and $M_{n y}$ are the nominal bending flexural capacities, along the principal cross-section axes.

The nominal column resistance $\left(P_{n}\right)$ is expressed as:

$$
P_{n}=A_{e f f} \cdot F_{n}
$$

where $F_{n}$ is the critical stress depending on the slenderness factor $\bar{\lambda}_{C}$ defined as:

$\bar{\lambda}_{C}=\sqrt{\frac{F_{y}}{F_{\text {cre }}}}$

with $F_{y}$ representing the tensile yield stress of the virgin material and $F_{c r e}$ is the least of the elastic (global flexural, torsional or flexural-torsional) buckling stresses evaluated with reference to the gross cross-section properties.

In particular:

$$
\begin{array}{ll}
\text { if } \quad \bar{\lambda}_{C} \leq 1.5 & F_{n}=\left(0.658^{\bar{\lambda}_{C}^{2}}\right) F_{y} \\
\text { - if } \quad \bar{\lambda}_{C}>1.5 & F_{n}=\left(\frac{0.877}{\bar{\lambda}_{C}^{2}}\right) F_{y}
\end{array}
$$

The beam moment resistance $\left(M_{n y}\right)$ accounting for lateral buckling is evaluated as:

$$
M_{n}=\left(S_{e f f} \cdot F_{n}\right)
$$

where $S_{\text {eff }}$ is the effective section modulus along the $x$-axis (symmetry) and $F_{n}$ is the global flexural stress depending by the critical elastic lateral-torsional buckling stress, $F_{c r e}$, and by the yield stress, $F_{y}$, by means of the following relationships:

$$
\begin{array}{ll}
\text { - if } \quad F_{c r e} \geq 2.78 F_{y} & F_{n}=F_{y} \\
\text { - if } \quad 2.78 F_{y}>F_{c r e}>0.56 F_{y} & F_{n}=\frac{10}{9} F_{y}\left(1-\frac{10 F_{y}}{36 F_{c r e}}\right) \\
\text { - if } \quad F_{c r e} \leq 0.56 F_{y} & F_{n}=F_{c r e}
\end{array}
$$

The beam moment resistance along the $y$-axis (non-symmetry axis) is given by the expression:

$$
M_{n y}=\left(S_{e f f, y} \cdot F_{y}\right)
$$

where $S_{\text {eff,y }}$ is effective section modulus.

US-DSM. Schafer and Pekoz [33] proposed the DSM approach, that is addressed in the AISI S100 Specifications [17]. In more detail, DSM includes a linear eigenvalue analysis of the elastic buckling behaviour based on the wellknown finite strip method [34,35] (comprising of local, distortional and global buckling modes). Unlike all previously presented approaches, it is not required to evaluate the effective cross-section geometric properties, i.e. the DSM method is applied directly to the gross cross-section. Actually, DSM has been proposed only for elements under pure compression or pure flexure and, in the following a linear relationship for the beam-column domains in the bending moment-axial force reference system is assumed, owing to the lack of practical indications in the code. In the case of compressed elements, the resistance is given by the minimum value between the global buckling resistance $\left(P_{n e}\right)$, the local buckling resistance $\left(P_{n l}\right)$ and the distortional buckling resistance $\left(P_{n d}\right)$.

The global buckling resistance is defined similarly to eq. 13). In particular, once evaluated the squash load $\left(P_{y}\right)$ and the overall critical load $\left(P_{c r e}\right)$, the overall buckling resistance, $P_{n e}$, is defined as:

$$
\begin{array}{ll}
\text { - if } \overline{\lambda_{C}} \leq 1.5 & P_{n e}=\left(0.658^{\bar{\lambda}_{C}^{2}}\right) P_{y} \\
\text { - if } \bar{\lambda}_{C}>1.5 & P_{n e}=\left(\frac{0.877}{\bar{\lambda}_{C}^{2}}\right) P_{y}
\end{array}
$$

being the slenderness factor $\bar{\lambda}_{C}$ defined as:

$$
\bar{\lambda}_{C}=\sqrt{\frac{P_{y}}{P_{c r e}}}
$$

The axial strength for local buckling $\left(P_{n l}\right)$ depends on the local slenderness factor $\bar{\lambda}_{l}$ defined as:

$$
\bar{\lambda}_{l}=\sqrt{\frac{P_{n e}}{P_{c r l}}}
$$

and

$$
\begin{aligned}
& \text { - if } \quad \bar{\lambda}_{l} \leq 0.776 \quad P_{n l}=P_{y} \\
& \text { - if } \bar{\lambda}_{l}>0.776 \quad P_{n l}=\left[1-0.15\left(\frac{P_{c r l}}{P_{n e}}\right)^{0.4}\right]\left(\frac{P_{c r l}}{P_{n e}}\right)^{0.4} \cdot P_{n e}
\end{aligned}
$$

where $P_{c r l}$ is the elastic critical load for local buckling.

The nominal axial strength for distortional buckling $\left(P_{n d}\right)$ depends on the distortional slenderness factor $\bar{\lambda}_{d}$ defined as:

$$
\bar{\lambda}_{d}=\sqrt{\frac{P_{y}}{P_{c r d}}}
$$

and

$$
\begin{aligned}
& \text { - if } \quad \bar{\lambda}_{d} \leq 0.561 \quad P_{n d}=P_{y} \\
& \text { - if } \bar{\lambda}_{d}>0.561 \quad P_{n l}=\left[1-0.25\left(\frac{P_{c r d}}{P_{n e}}\right)^{0.6}\right]\left(\frac{P_{c r d}}{P_{n e}}\right)^{0.6} \cdot P_{n e}
\end{aligned}
$$

where $P_{c r l}$ is the elastic critical load for distortional buckling.

The overall $\left(P_{c r e}\right)$, local $\left(P_{c r l}\right)$ and distortional $\left(P_{c r d}\right)$ critical buckling loads, can be easily obtained by using the tools available [36-38] for the study of TWCF members. Fig. 7 shows the typical relationship between the critical load and the half-wave length by considering all the relevant buckling modes, obtained by means of the CUFSM software developed and freely offered by Schafer [36].

Similarly, in the case of elements subjected to bending, the flexural resistance is given by the minimum value between the beam moment resistance $\left(M_{n x}\right)$ accounting for lateral buckling $\left(M_{n e}\right)$, local $\left(M_{n l}\right)$ and distortional buckling flexural $\left(M_{n d}\right)$ resistance.

For the global buckling resistance $\left(M_{n e}\right)$, the following relationships have to be considered:

$$
\text { - if } M_{c r e} \geq 2.78 M_{y} \quad M_{n e}=M_{y}
$$


- if $2.78 M_{y}>M_{c r e}>0.56 M_{y} \quad M_{n e}=\frac{10}{9} F_{y}\left(1-\frac{10 M_{y}}{36 M_{c r e}}\right)$

- if $M_{c r e} \leq 0.56 M_{y}$

$$
M_{n e}=M_{c r e}
$$

where $M_{\text {cre }}$ is the elastic critical moment for global buckling and $M_{y}$ is the yield moment.

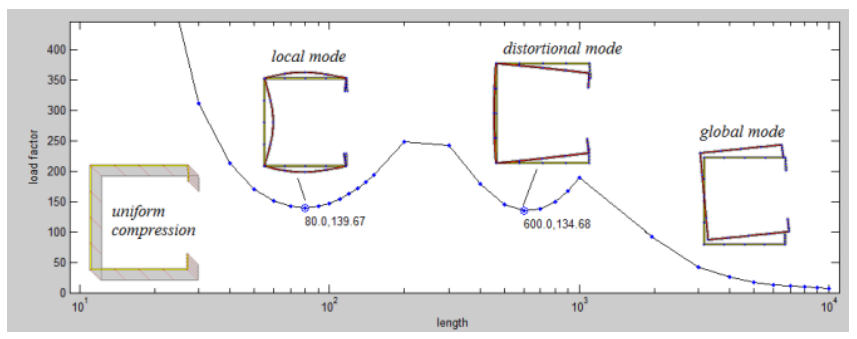

Fig. 7 Evaluation of local and distortional buckling loads for an element under compression (obtained by using CUFSM software by prof. Schafer [36])

In case of elements in bending, the flexural resistance for local buckling $\left(M_{n l}\right)$ depends on the local slenderness factor $\bar{\lambda}_{l}$ defined as:

$$
\bar{\lambda}_{l}=\sqrt{\frac{M_{n e}}{M_{c r l}}}
$$

and

$$
\begin{array}{lll}
\text { - if } & \bar{\lambda}_{l} \leq 0.776 & M_{n l}=M_{n e} \\
\text { - if } \quad \bar{\lambda}_{l}>0.776 & M_{n l}=\left[1-0.15\left(\frac{M_{c r l}}{M_{n e}}\right)^{0.4}\right]\left(\frac{M_{c r l}}{M_{n e}}\right)^{0.4} \cdot M_{n e}
\end{array}
$$

where $M_{c r l}$ is the elastic critical moment for local buckling.

The nominal flexural strength for distortional buckling $\left(M_{n d}\right)$ depends on the associated slenderness factor $\bar{\lambda}_{d}$ defined as:

$$
\bar{\lambda}_{d}=\sqrt{\frac{M_{y}}{M_{c r d}}}
$$

and

$$
\begin{array}{lll}
\text { - if } & \bar{\lambda}_{d} \leq 0.673 & M_{n d}=M_{y} \\
\text { - if } & \bar{\lambda}_{d}>0.673 & M_{n d}=\left[1-0.22\left(\frac{M_{c r d}}{M_{y}}\right)^{0.5}\right]\left(\frac{M_{c r d}}{M_{y}}\right)^{0.5} \cdot M_{y}
\end{array}
$$

\section{where $M_{c r d}$ is the elastic critical moment for distortional buckling}

Also in this case, the critical elastic moments for global $\left(M_{c r e}\right)$, local $\left(M_{c r l}\right)$ and distortional $\left(M_{c r d}\right)$ buckling modes can be easily obtained by finite strip analysis. Fig. 8 can be considered as an example of the relationship between the critical moment versus the half-wave length accounting for the relevant buckling modes.

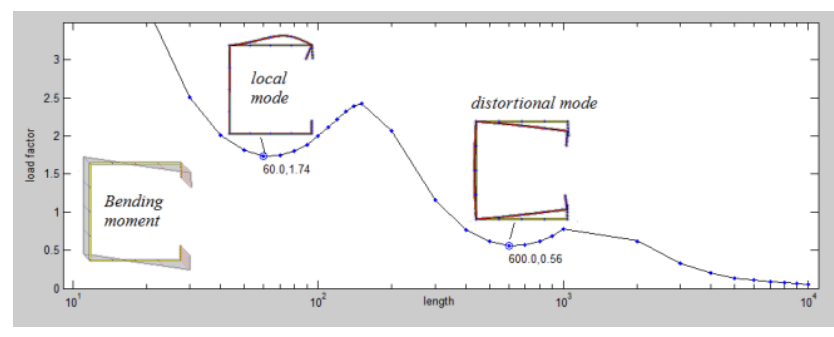

Fig. 8 Evaluation of local and distortional buckling moments for an element under bending (obtained by using CUFSM software by prof. Schafer [36])

Furthermore, it is worth mentioning that the DSM approach will probably be included among the European alternatives to design TWCF members in the next few years, as attested by the recent attention paid in Europe by researchers $[39,40]$. Finally, in the Authors' opinion, DSM seems also very promising if applied to the design of steel storage uprights, i.e. TWCF perforated members that are the vertical elements of the skeleton frame directly supporting goods and materials, as demonstrated by the recent researches of Casafont et al. [41]

\begin{tabular}{|c|c|c|c|c|c|c|c|}
\hline & \multicolumn{5}{|c|}{ EU approaches } & \multicolumn{2}{|c|}{ US approaches } \\
\hline & $1-3$ & GEM & ENV & $1-1 \mathrm{~A}$ & $1-1 \mathrm{~B}$ & EWM & DSM \\
\hline Effective geometric properties & $\mathrm{Y}$ & $\mathrm{Y}$ & $\mathrm{Y}$ & $\mathrm{Y}$ & $\mathrm{Y}$ & $\mathrm{Y}$ & $\mathrm{N}$ \\
\hline $\begin{array}{l}\text { Secondary bending moments } \\
\text { due to the shift of the centroids }\end{array}$ & $\mathrm{Y}$ & $\mathrm{Y}$ & $\mathrm{Y}$ & $\mathrm{Y}$ & $\mathrm{Y}$ & $\mathrm{Y}$ & $\mathrm{N}$ \\
\hline Equivalent moment coefficient & $\mathrm{N}$ & $\mathrm{N}$ & $\mathrm{Y}$ & $\mathrm{Y}$ & $\mathrm{Y}$ & $\mathrm{Y}$ & $\mathrm{Y}$ \\
\hline $\begin{array}{l}\text { Direct interaction between dif- } \\
\text { ferent buckling modes }\end{array}$ & $\mathrm{N}$ & $\mathrm{N}$ & $\mathrm{N}$ & $\mathrm{N}$ & $\mathrm{N}$ & $\mathrm{Y}$ & $\mathrm{Y}$ \\
\hline M-N linear domain & $\mathrm{N}$ & $\mathrm{N}$ & $\mathrm{N}$ & $\mathrm{N}$ & $\mathrm{N}$ & $\mathrm{Y}$ & $\mathrm{Y}$ \\
\hline Mandatory code alternative & $\mathrm{Y}$ & $\mathrm{Y}$ & $\mathrm{N}$ & $\mathrm{N}$ & $\mathrm{N}$ & $\mathrm{Y}$ & $\mathrm{Y}$ \\
\hline
\end{tabular}
VijayaVengadesh [42], VijayaVengadesh and Arul Jayachandran [43] and Moen [44].

\section{Comparison between the different approaches}

Table 1

Similarities and differences related to the EU and US approaches for TWCF members

$\mathrm{N}=\mathrm{No} ; \mathrm{Y}=\mathrm{Yes}$

As discussed in the previous sections, EU and US standards offer to designers different options for the verification checks of isolated members subjected to axial force and bending moments. The main similarities and differences are pointed out in Table 1. In particular, it is worth noting that:

- all the approaches are based on the theoretical assessment of the effective geometric properties under compression and bending, with the sole exception of the US-DSM;

- a quite complex evaluation of the equivalent moment coefficients is required only by ENV, 1-1A and 1-1B approaches. Otherwise, the maximum value of the bending moment on the member along each principal axis have to be considered;

- all the approaches need complex calculations with the exception of the DSM method which requires the definition of the complete buckling curve considering all the possible critical buckling modes, including the local and distortional ones. In this case, suitable free tools are however offered to engineers for routine design;

- only the EC3-1-3, GEM, EWM and DSM approaches are presently mandatory.

The interest is hence to investigate how these similarities and differences could eventually reflect in the member resistance. Attention has consequently been focused on simply supported beam-columns under moment gradient, which are frequently encountered in routine design. Both cases of equal and opposite bending end moments along the axis of symmetry have been investigated by considering the presence of a constant bending moment in the symmetry plane accounting for the gross-to-effective centroid shift. The crosssection is a typical lipped channel with a stiffened web made of steel grade S355 [45], with yield and ultimate nominal strength of $355 \mathrm{~N} / \mathrm{mm}^{2}$ and $490 \mathrm{~N} / \mathrm{mm}^{2}$, respectively. Owing to the confidentiality required by the steel manufacture, the geometry of this cross-section cannot be herein directly presented. However, it is worth noting that the domains proposed in the following and the associated outcomes are, in general, adequately representative for any type of TWCF members, independently of the cross-section type and slenderness of its plates.

At first, attention is focused on the domains drawn according with the European approaches, which are proposed in Figs. 9 and 10. They are related to the cases of equal and opposite end moments, respectively, by considering quite stocky and slender members, corresponding to a relative minimum slenderness for axial buckling (eq. 7a) of $\bar{\lambda}_{\text {min }}=0.6$ (solid lines) and $\bar{\lambda}_{\min }=1.5$ (dashed lines), respectively. For the limit case of a beam, i.e. a member under mono-axial flexure, lacking the axial force and hence the associated secondary moment due to the centroid shift, all the approaches lead to similar values of flexural resistance: differences are within $5 \%$ and are mainly due to the absence of the equivalent moment factor in the GEM and 1-3 approaches. For what concerns member response to pure compression (and secondary bending along the symmetry plane), the load carrying capacities are practically equal if the 1 3, 1-1A, 1-1B and GEM approaches are compared (difference within 2\%): the 1-3 approach is slightly more conservative than the others and differences are up to $17 \%$, owing to the presence of the exponent $(0.8)$ in the interaction domain in eq. $4 \mathrm{~b}$ ). As far as the beam-column domains are concerned, the interaction formula associated with the ENV approach defines a linear domain between the 
axial force and the bending moment. Furthermore, the most conservative approach is the 1-3, which always defines a convex domain, independently of the member slenderness and of the bending moment distribution. In case of constant moment (Fig. 9), no significant differences can be detected between the 1-1A, 1-1B, ENV and GEM approaches: a moderate difference is observed if these four domains are compared with those of the 1-3 approach defining a slightly concave (and hence, in general, more severe) domain.

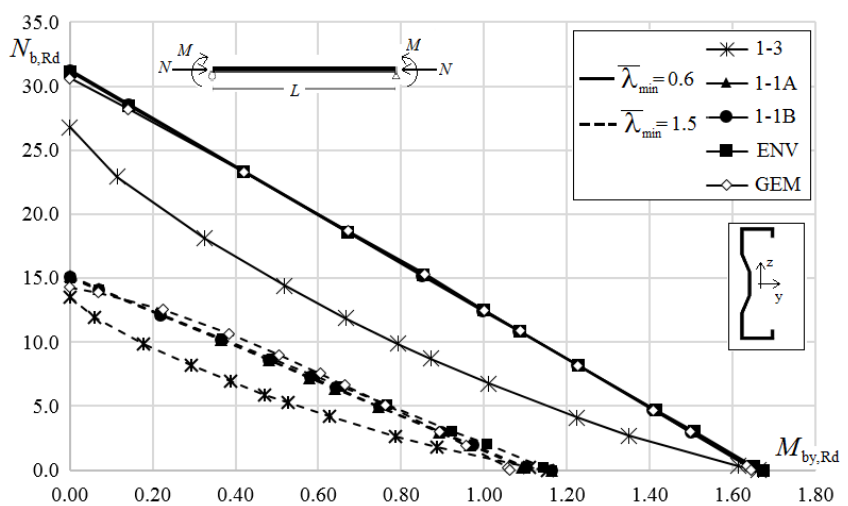

Fig. 9 Typical beam-column EU domains for the case of constant bending moment

In the case of moment gradient (Fig. 10), the previous remarks on the limit cases of beams and columns are confirmed, while, in case of beam-columns, the differences between the considered approaches are more evident with respect to the case of constant end moments, especially by comparing the 1-1A, GEM and ENV domains. The least conservative performances are guaranteed by the 1-1B approach, especially for the greatest value of slenderness while the most severe is again associated with the 1-3 approach.

As to the US domains, owing to the need to focus attention on the key innovative issues of the research, it has been decided to consider only the DSM approach, considering that EWM is based on the evaluation of the effective geometric parameters like all the EU methods. In particular, the same practical cases already discussed for the EU alternatives have been considered. Figs. 11 and 12, corresponding to Figs. 9 and 10, respectively, present the DSM domains compared with those of the 1-3 and GEM approaches, which are the most commonly adopted in practical design according to the $\mathrm{EU}$ alternatives.

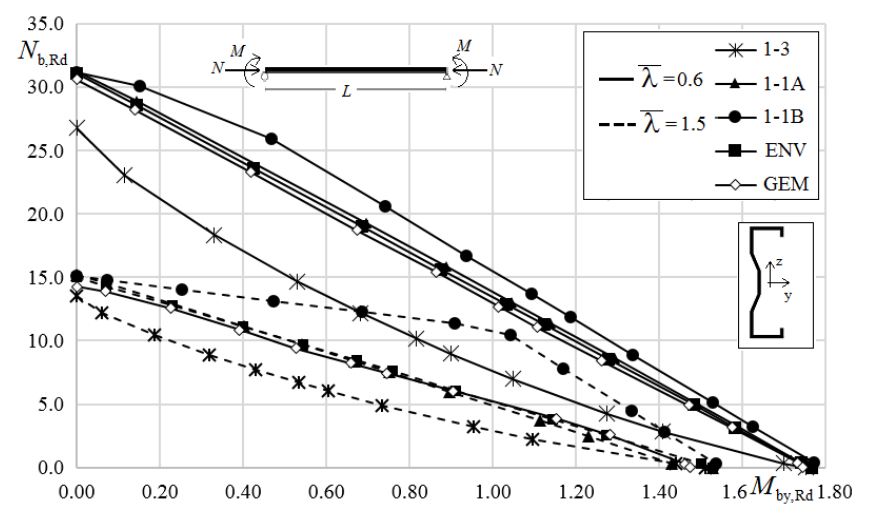

Fig. 10 Typical beam-column EU domains for the case of opposite end bending moments

As to the ideal cases of columns, it can be noted that the DSM approach leads to a less conservative assessment of the load carrying capacity if compared to the 1-3 approach, up to $6 \%$ and $10 \%$, for $\bar{\lambda}_{\text {min }}=0.6$ and $\bar{\lambda}_{\text {min }}=1.5$, respectively. Otherwise, DSM is slightly more conservative than GEM but differences are however not greater than $3 \%$. As to beams, non-negligible differences are observed independently of the member slenderness and bending moment diagram: the DSM approach is the most conservative, up to $30 \%$ and $34 \%$ with respect to 1-3 and GEM approaches, respectively. As to the beamcolumn domains, the DSM trend has been assumed to be linear and only for high values of the applied axial force, DSM appears to be less conservative than $1-3$; otherwise, increasing the value of the bending moments, DSM becomes the most conservative approach.

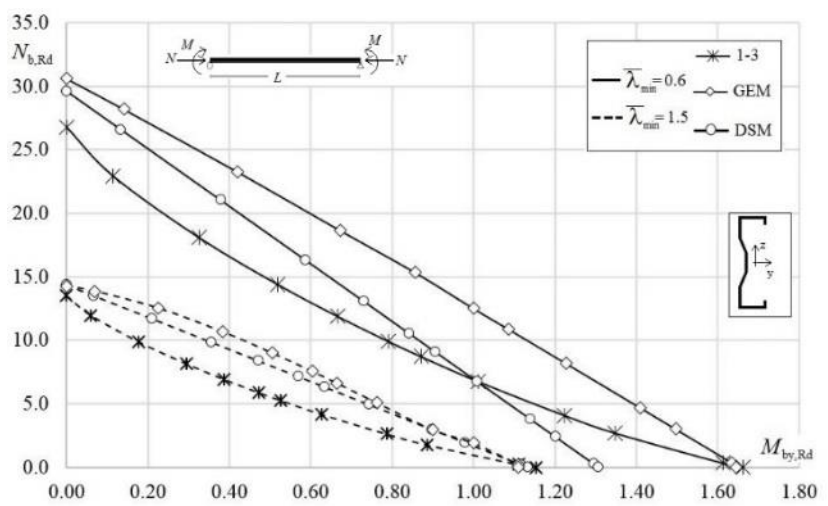

Fig. 11 Typical beam-column EU and US domains for constant bending moment

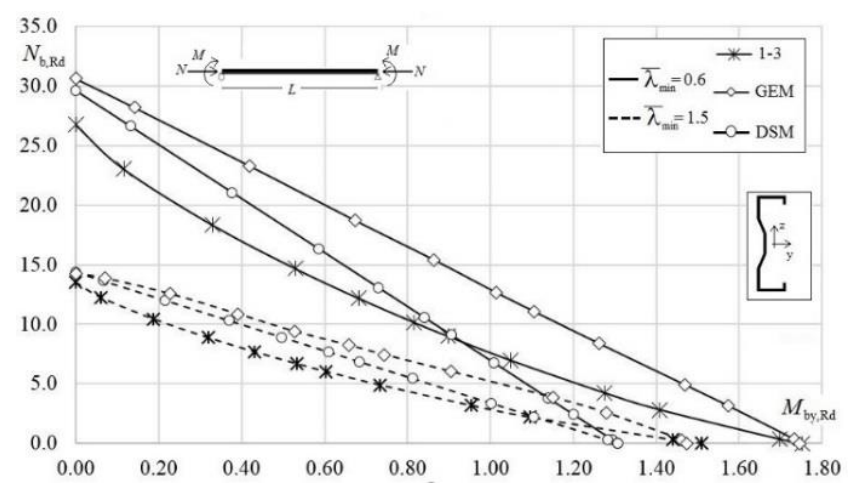

Fig. 12 Typical beam-column EU and US domains for opposite bending moments

A summary of the Figs. 9-12, which are of great interest for practical design purposes, is proposed in Table 2, where selected values of the couple axial force-bending moment have been considered, in terms of load carrying capacity (LCC), which is identified via the $\alpha_{e c c}$ angle representing the angle between the vertical (axial) axis and a generic straight line through the origin (Fig. 13). In case of columns and beams, the LCC coincides with the axial and flexural resistance, respectively.

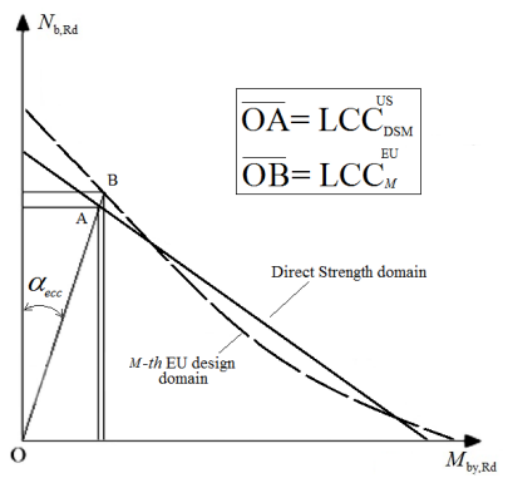

Fig. 13 Details for the identification of the cases considered in Table 3

The following values of $\alpha_{e c c}$ have been considered: $0^{\circ}$ (only axial force and secondary bending moment along the non-symmetry axis), $2^{\circ}, 5^{\circ}, 30^{\circ}, 45^{\circ}, 75^{\circ}$ and $90^{\circ}$ (pure flexure along both axes). These values have been selected to obtain a representative approximation of the whole domain. In order to allow for a direct comparison, the load carrying capacities associated with the considered EU alternatives have been divided by the one obtained via the USDSM approach, that is the sole method based on the gross cross-section geometry. In the Table 2, for each set of data defining the domain, the mean (mean), the maximum (Max) and the minimum $(\mathrm{min})$ values are reported together with the standard deviation (dev.) evaluated according to eq. 31) by assuming the number of data equal to seven. From those data, it appears that the differences in terms of LCC are not negligible for practical design purposes. In case of the 1-3 approach, which is the most conservative among the EU alternatives, the ratio $L C C_{1-3}^{E U} / L C C_{D S M}^{U S}$ ranges from 0.88 and 1.34 for stocky members while it is comprised between 0.83 and 1.15 for slender members. 
Table 2

Load carrying capacity of the EU alternatives over the DSM one

\begin{tabular}{|c|c|c|c|c|c|c|c|c|c|c|c|}
\hline \multirow[b]{3}{*}{$\overline{\lambda_{m \iota n}}$} & \multirow[b]{3}{*}{$\begin{array}{c}\alpha_{e c c} \\
{[\mathrm{deg}]}\end{array}$} & \multicolumn{10}{|c|}{ Bending moment distribution type } \\
\hline & & \multicolumn{5}{|c|}{ Equal end moments } & \multicolumn{5}{|c|}{ Opposite end moments } \\
\hline & & $\frac{L C C_{1-3}^{E U}}{L C C_{D S M}^{U S}}$ & $\frac{L C C_{G E M}^{E U}}{L C C_{D S M}^{U S}}$ & $\frac{L C C_{E N V}^{E U}}{L C C_{D S M}^{U S}}$ & $\frac{L C C_{1-1 A}^{E U}}{L C C_{D S M}^{U S}}$ & $\frac{L C C_{1-1 B}^{E U}}{L C C_{D S M}^{U S}}$ & $\frac{L C C_{1-3}^{E U}}{L C C_{D S M}^{U S}}$ & $\frac{L C C_{G E M}^{E U}}{L C C_{D S M}^{U S}}$ & $\frac{L C C_{E N V}^{E U}}{L C C_{D S M}^{U S}}$ & $\frac{L C C_{1-1 A}^{E U}}{L C C_{D S M}^{U S}}$ & $\frac{L C C_{1-1 B}^{E U}}{L C C_{D S M}^{U S}}$ \\
\hline \multirow{11}{*}{0.6} & $0^{\circ}$ & 0.90 & 1.03 & 1.05 & 1.06 & 1.05 & 0.90 & 1.03 & 1.05 & 1.06 & 1.05 \\
\hline & $2^{\circ}$ & 0.88 & 1.14 & 1.14 & 1.14 & 1.14 & 0.90 & 1.15 & 1.17 & 1.18 & 1.26 \\
\hline & $5^{\circ}$ & 0.96 & 1.20 & 1.20 & 1.20 & 1.19 & 0.99 & 1.22 & 1.24 & 1.26 & 1.31 \\
\hline & $30^{\circ}$ & 1.07 & 1.24 & 1.24 & 1.24 & 1.24 & 1.12 & 1.29 & 1.30 & 1.31 & 1.34 \\
\hline & $45^{\circ}$ & 1.12 & 1.25 & 1.25 & 1.25 & 1.25 & 1.17 & 1.31 & 1.32 & 1.32 & 1.35 \\
\hline & $75^{\circ}$ & 1.25 & 1.26 & 1.27 & 1.27 & 1.27 & 1.31 & 1.34 & 1.34 & 1.34 & 1.37 \\
\hline & $90^{\circ}$ & 1.27 & 1.26 & 1.28 & 1.28 & 1.28 & 1.34 & 1.34 & 1.35 & 1.35 & 1.35 \\
\hline & mean & 1.07 & 1.20 & 1.21 & 1.21 & 1.20 & 1.11 & 1.24 & 1.25 & 1.26 & 1.29 \\
\hline & dev. & 0.1575 & 0.0830 & 0.0838 & 0.0808 & 0.0811 & 0.1814 & 0.1135 & 0.1100 & 0.1068 & 0.1101 \\
\hline & $\operatorname{Max}$ & 1.27 & 1.26 & 1.28 & 1.28 & 1.28 & 1.34 & 1.34 & 1.35 & 1.35 & 1.37 \\
\hline & Min & 0.88 & 1.03 & 1.05 & 1.06 & 1.05 & 0.90 & 1.03 & 1.05 & 1.06 & 1.05 \\
\hline \multirow{11}{*}{1.5} & $0^{\circ}$ & 0.94 & 0.99 & 1.05 & 1.06 & 1.05 & 0.94 & 0.99 & 1.05 & 1.06 & 1.05 \\
\hline & $2^{\circ}$ & 0.83 & 1.08 & 1.04 & 1.03 & 1.03 & 0.86 & 1.06 & 1.08 & 1.08 & 1.28 \\
\hline & $5^{\circ}$ & 0.83 & 1.05 & 1.03 & 1.01 & 1.01 & 0.88 & 1.09 & 1.11 & 1.10 & 1.52 \\
\hline & $30^{\circ}$ & 0.88 & 0.99 & 1.03 & 0.99 & 1.00 & 0.95 & 1.15 & 1.14 & 1.11 & 1.33 \\
\hline & $45^{\circ}$ & 0.90 & 0.98 & 1.03 & 0.99 & 0.99 & 0.99 & 1.16 & 1.15 & 1.11 & 1.28 \\
\hline & $75^{\circ}$ & 0.99 & 0.95 & 1.02 & 0.98 & 0.99 & 1.12 & 1.14 & 1.17 & 1.11 & 1.20 \\
\hline & $90^{\circ}$ & 1.02 & 0.98 & 1.03 & 1.03 & 1.03 & 1.15 & 1.13 & 1.17 & 1.17 & 1.17 \\
\hline & mean & 0.91 & 1.00 & 1.03 & 1.01 & 1.01 & 0.99 & 1.10 & 1.12 & 1.11 & 1.26 \\
\hline & dev. & 0.0750 & 0.0459 & 0.0080 & 0.0286 & 0.0230 & 0.1129 & 0.0597 & 0.0470 & 0.0342 & 0.1473 \\
\hline & $\operatorname{Max}$ & 1.02 & 1.08 & 1.05 & 1.06 & 1.05 & 1.15 & 1.16 & 1.17 & 1.17 & 1.52 \\
\hline & Min & 0.83 & 0.95 & 1.02 & 0.98 & 0.99 & 0.86 & 0.99 & 1.05 & 1.06 & 1.05 \\
\hline
\end{tabular}

The GEM approach results on average $22 \%$ less conservative than the DSM one for $\bar{\lambda}_{\min }=0.6$ and $5 \%$ for $\bar{\lambda}_{\min }=1.5$. No great differences can be observed for the remaining alternatives, with the exception of the 1-1B approach, that has been already identified as the least conservative. In this case, the associated ratio reaches the value of 1.52 for opposite moment on the slender elements, significantly higher than the ones corresponding to the other approaches, never greater than 1.17 . It can hence be preliminarily concluded that these alternatives are not equivalent to each other and these different values of the LCC are expected to have a great impact on the design and consequently on the cost and the competitiveness of the products on the market.

\section{Experimental assessment of the TWCF member performance}

With the exception of the DSM approach, as already mentioned, the other procedures considered in this paper require to theoretically assess the effective resisting cross-sections. Two weakness points associated with the effective width method are i) its field of applicability, which is limited only to few typical cross-section types (i.e. mainly lipped channels and zed, owing to the difficulties of defining the local/distortional buckling interaction), and ii) the ambiguity in few statements, found in codes, that can be interpreted in different ways, as already observed $[46,47]$. In order to overcome these problems, a "design assisted by testing" procedure could be alternatively adopted, according, as an example, to the general requirements of Appendix D ("Design assisted by testing") of EN1990 [48] and to the indications addressed in Appendix A ("Testing procedure") of EN 1993-1-3 [16]. In particular, the key step is the definition of the characteristic value of the considered design performance. To this end, two alternatives are prescribed, depending on the number of tests on nominally equal specimen is small or large. In the former case, the number of specimens is limited to three. The characteristic parameter of interest $R_{k}$ associated in case of a sole individual test $R_{i}$, eventually adjusted/corrected for thickness and yield stress, can be estimated as:

$$
R_{k}=0.9 \cdot \eta_{k} \cdot R_{i}
$$

where $\eta_{k}$ depends strictly on failure modes such as yielding failure $\left(\eta_{k}=0.9\right)$, gross deformation ( $\eta_{k}=0.9$ ), local buckling (from $\eta_{k}=0.8$ to $\eta_{k}=0.9$ depending on effects on global behavior in tests) and overall instability $\left(\eta_{k}=0.7\right)$.

For a family of two or three tests, provided that each $R_{i}$ value is within \pm $10 \%$ of the mean value $R_{m}$ of all the test results, $R_{k}$ is defined as:
In case of a large number of specimens, i.e. when the number of tests (n) on nominally equal specimens is not less than three, $R_{k}$ can be assessed as:

$$
R_{k}=R_{m}-k_{s} \cdot s
$$

where $R_{m}$ is the mean value of the adjusted test results, $k_{s}$ is the well-known coefficient based on $95 \%$ fractile at a confidence level of $75 \%$ (Table 3) and $s$ is the standard deviation defined as:

$$
s=\sqrt{\frac{1}{n-1} \sum_{i=1}^{n}\left(R_{i}-R_{m}\right)^{2}}
$$

Table 3

Values of the $k_{s}$ coefficients

\begin{tabular}{cccccccccc}
\hline$n$ & 3 & 4 & 5 & 6 & 8 & 10 & 20 & 30 & $\infty$ \\
\hline$k_{s}$ & 3.37 & 2.63 & 2.33 & 2.18 & 2.08 & 1.92 & 1.76 & 1.73 & 1.64 \\
\hline
\end{tabular}

If design assisted-by-testing is adopted to assess directly the axial or the flexural resistance, by means of stub column tests (Fig. 14), compressive tests or bending tests, the design values can be obtained directly by using the material safety coefficient $\gamma_{M}$ reducing the characteristic value obtained by means of eqs. 28)-30).
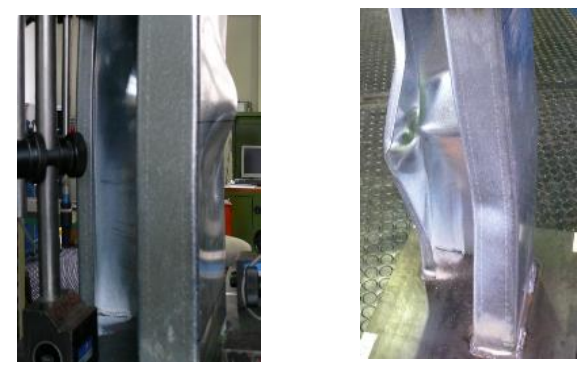

Fig. 14 Collapse of lipped angle specimen for interaction between local and distortional buckling

\section{Experimental validation of the design procedures}

An open question of outstanding interest from the practical point of view is 
associated with the evaluation of the actual level of safety of the design approaches discussed in the previous sections: in other words, if the EU-1-1A approach is on the safe side, all the others, and especially the EU-1-3 and USDSM approach, should result greatly conservative. Otherwise, if the US-DSM, or the EU-1-3 are unconservative, a fortiori, the others lead to a design that should be dangerously unsafe. Experimental results could hence be really useful to define the actual degree of accuracy of the different design alternatives but in many researches, only one or at least two nominally equal specimens have been tested. Test results are in general directly compared by researchers with the results associated with one design approach without any rigorous definition of the characteristic and design experimental values. The sole exception is represented by few experimental campaigns that were carried out on a large number of nominally equal specimens, which have been considered in the present study. The final aim is to compare the experimental load carrying capacity suitably assessed via a statistical re-elaboration of the experimental data according to eq. 30) with the performance estimated by using the discussed design alternatives. In the following, reference is made to four experimental studies [49-54] characterized by tests on three or more nominally equal specimens, i.e. on a more than adequate number of tests for a statistical analysis matching the limit state design philosophy.

A summary of the considered cross-sections is shown in Table 4 where the slenderness of the web $(h / t)$, of the flanges $(b / t)$ and of the lip $(c / t)$ are reported together with the length of the tested specimens and the ratio between the distance $\left(d_{g}\right)$ between the gross-section centroid and the web over the distance between the effective cross-section centroid and the web $\left(d_{e f f}\right)$. In the case of lipped channels, the $\mathrm{d}_{\mathrm{g}} / \mathrm{d}_{\text {eff }}$ ratio is lower than unity, ranging between 0.842 and 0.987 : secondary bending moments induce tension on the web. Otherwise, with plane channels as well as with lipped channels with stiffened web the effective crosssection centroid moves close to the web, inducing a non-negligible secondary moment with compression on the web.

Table 4

The considered cross-section type

\begin{tabular}{|c|c|c|c|c|c|c|c|}
\hline ID & $h / t$ & $b / t$ & $c / t$ & $\begin{array}{c}L_{0} \\
{[\mathrm{~mm}]}\end{array}$ & $d_{g} / d_{e f f}$ & Cross-section & Reference \\
\hline U2 & 48.00 & 24.00 & 7.00 & 370 & 0.946 & ר & \multirow{3}{*}{ [49] } \\
\hline $\mathrm{U} 1.2$ & 80.00 & 41.33 & 12.33 & 360 & 0.916 & & \\
\hline U0.8 & 120.00 & 63.00 & 19.00 & 360 & 0.896 & لـ & \\
\hline UNLIP1 & 66.79 & 40.91 & - & 400 & 3.763 & & \multirow{3}{*}[50,51]{} \\
\hline UNLIP2 & 66.11 & 40.56 & - & 398 & 3.724 & & \\
\hline UNLIP3 & 64.63 & 38.33 & - & 398 & 3.585 & & \\
\hline LIP1 & 81.34 & 43.61 & 13.89 & 400.2 & 0.985 & & \multirow{4}{*}[50,51]{} \\
\hline LIP2 & 84.08 & 45.08 & 14.36 & 398 & 0.987 & & \\
\hline LIP3 & 83.09 & 44.59 & 13.43 & 402.5 & 0.984 & & \\
\hline LIP4 & 84.12 & 44.92 & 13.66 & 400 & 0.987 & & \\
\hline $\mathrm{C} 1-\mathrm{C} 3$ & 76.42 & 73.58 & 11.32 & 2850 & 0.818 & 1 & \multirow{3}{*}{ [52] } \\
\hline $\mathrm{C} 4-\mathrm{C} 6$ & 70.09 & 60.75 & 10.28 & 2350 & 0.851 & & \\
\hline $\mathrm{A} 100$ & 100.00 & 57.00 & 4.90 & $300-550$ & 1.239 & J & \\
\hline B100 & 83.33 & 47.50 & 4.08 & $300-550$ & 1.215 & & \multirow{5}{*}[53,54]{} \\
\hline A150 & 150.00 & 57.00 & 4.90 & $350-650$ & 1.294 & & \\
\hline B150 & 125.00 & 47.50 & 4.08 & $350-650$ & 1.277 & & \\
\hline A 200 & 200.00 & 57.00 & 4.90 & $450-750$ & 1.183 & & \\
\hline B200 & 166.67 & 47.50 & 4.08 & $450-750$ & 1.234 & & \\
\hline
\end{tabular}

In particular, useful data have been derived from the following researches:

- in 1992, Pu et al. [4,9] investigated the behavior of solid and perforated lipped channels, focusing attention on the prediction of the ultimate load capacity. Several specimens were tested differing for the presence and position of perforations as well as for their geometry. Referring to the cases of solid cross-sections, which is of interest for the present paper, 3 different thicknesses $(2 \mathrm{~mm}, 1.2 \mathrm{~mm}$ and $0.8 \mathrm{~mm}$ ) have been considered and for each of them 3 nominally equal specimens have been tested;

- in 2003, Feng et al. [50,51] analyzed the influence of the temperature on the response of plain as well as lipped channel columns. Only data related to ambient temperature tests are herein considered and in particular, 3 tests on plain channels and 4 tests on lipped channels;

- in 2012, dos Santos et al. [52], focused attention on stainless steel lipped channels and tested two series of specimens, differing for the materials and for the procedure adopted to ensure fixed column end supports. Two sets of results, each of them related to three nominally equal specimens, have been considered in the present study;

- in 2014, Baldassino et al. [53,54] executed stub column tests on 6 different lipped channel cross-sections with stiffened web. Three cross-section types have been considered, differing for the web height (i.e. $100 \mathrm{~mm}, 150 \mathrm{~mm}$ and $200 \mathrm{~mm}$ ). For each of them, two different thicknesses were considered: $1 \mathrm{~mm}$ and $1.2 \mathrm{~mm}$ were used for A and B specimens, respectively. For each web height and for each thickness, three set of stub-column tests on different column length were carried out on five nominally equal specimens. It is worth noting that Figs. 9-12 are related to the A200 cross-section type.

For all these specimens, the theoretical load carrying capacity has been evaluated according to the European 1-3, GEM, ENV, 1-1A and 1-1B and United States DSM approaches. It can be noted that all the considered specimens satisfy the requirements for the applicability of the considered design approaches.

Two different alternatives can be adopted to assess the degree of accuracy of the design approaches on the basis of experimental data. The first is to compare directly the load carrying capacity associated with the generic $M$-th approach according to the $L$-code $\left(L C C_{M}^{L}\right)$ with the single test result, indicated in the following as $L C C_{E X P}$, and this is the way most commonly adopted by researchers. In this way it is not possible however to assess the reliability of the method with respect to the requirements associated with the semi-probabilistic limit state design methods. The second, is to compare $L C C_{M}^{L}$ with the associated experimental design value $\left(L C C_{E X P}^{D E S}\right)$, obtained by means of a statistical reelaboration of test data, according to the procedures previously discussed. In the following, according to EC3-1-3 $\gamma_{M}=1$ has been assumed, i.e. the design value is coincident with the characteristic one.

Figs. 15 and 16 present the results related to the $L C C_{M}^{L} / L C C_{E X P}^{D E S}$ and $L C C_{M}^{L} / L C C_{E X P}$ ratios grouping the 1-1A, 1-1B, GEM and ENV results in the first and the DSM and 1-3 results in the second Fig.. In both Figs., straight lines in correspondence of unity allow to appraise directly when the theoretical method is on the safe or unsafe side, i.e. the ratio is lower or greater than 1, respectively. Furthermore, a red box, grouping the $L C C_{M}^{L} / L C C_{E X P}^{D E S}>1$ and $L C C_{M}^{L} / L C C_{E X P}<$ 1 points, identifies the cases where the theoretical method is safe only with respect to a direct comparison with the experimental data, i.e. the experimental design performance is lower than the theoretical one.

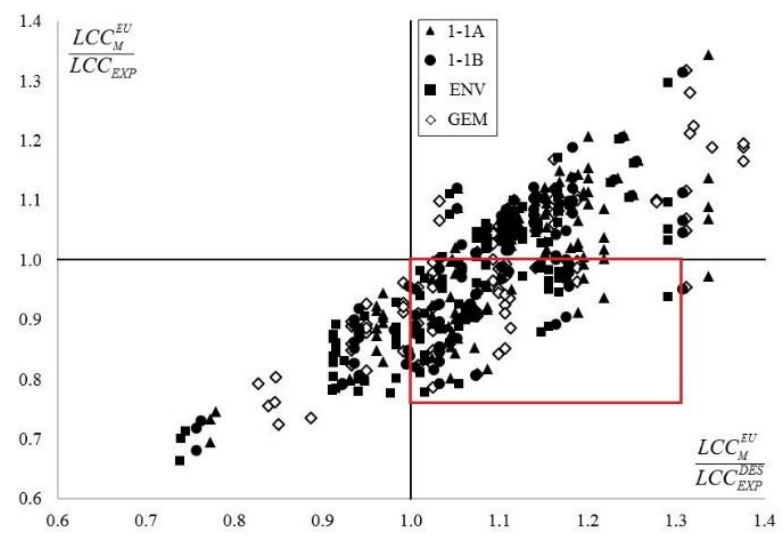

Fig. $15 \mathrm{LCC}_{\mathrm{M}}^{\mathrm{EU}} / \mathrm{LCC}_{\mathrm{EXP}}^{\mathrm{DES}}$ versus $\mathrm{LCC}_{\mathrm{M}}^{\mathrm{EU}} / \mathrm{LCC}_{\mathrm{EXP}}$ ratio for the 1-1A, 1-1B, GEM and ENV approaches

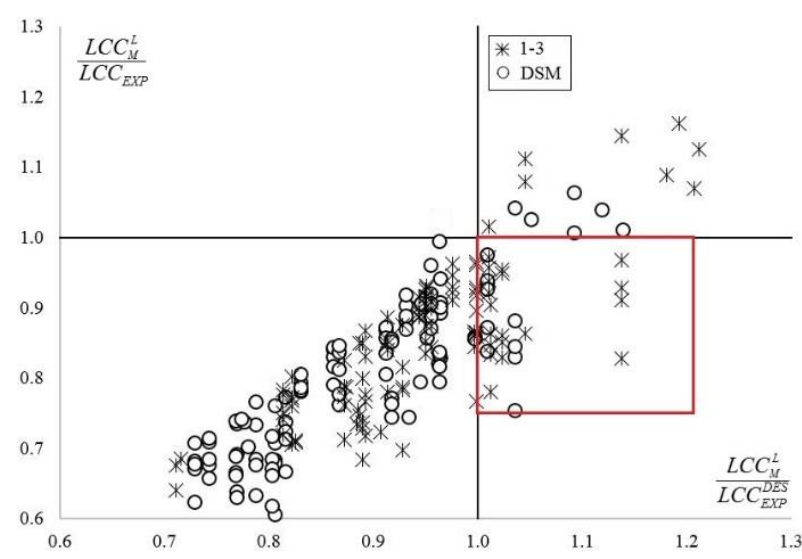

Fig. 16 $\mathrm{LCC}_{\mathrm{M}}^{\mathrm{L}} / \mathrm{LCC} \mathrm{EXP}_{\mathrm{EP}}^{\mathrm{DES}}$ versus $\mathrm{LCC}_{\mathrm{M}}^{\mathrm{L}} / \mathrm{LCC}_{\mathrm{EXP}}$ ratio for the 1-3 and DESM approaches

By considering the first set of approaches (i.e. 1-1A, 1-1B, ENV and GEM) in $17 \%$ of the cases both $L C C_{M}^{L} / L C C_{E X P}^{D E S}$ and $L C C_{M}^{L} / L C C_{E X P}$ values are lower than unity, while in $48 \%$ they both exceed unity. In the remaining cases, (approximately 35\% of the total cases) the direct use of the experimental data reflects the mistaken belief that the method is on the safe side. Otherwise, by 
considering Fig. 16, which is related to the 1-3 and DSM approaches, it can be observed that unity is exceeded or not by both the ratios in $6 \%$ and $80 \%$ of the cases, respectively. The data in the red box are mainly related to the 1-3 approach, considering that points representative of the DSM is quite limited (only $14 \%$ of the total points within the box). Independently of the method to assess the structural performance, a non-negligible discrepancy between the experimental result and the predicted theoretical one clearly appears.

Furthermore, to compare directly these design alternatives with reference to the two approaches to deal with experimental data, Fig. 17 proposes the cumulative density function (CDF) of the $L C C_{M}^{L} / L C C_{E X P S}^{D E S}$ (solid line) and $L C C_{M}^{L} /$ $L C C_{E X P}$ (dashed line) ratios related to the sole 1-3, GEM and DSM approaches, which are the most commonly adopted. According to the limit state design philosophy reference can be made to the $95 \%$ fractile value that is directly boxed in the Fig.: this characteristic value ranges from 0.99 to 1.20 and from 1.04 to 1.33 if reference is made to the experimental and to the design experimental strength, respectively. It is confirmed that, in general, the most conservative approach is the DSM, even though in a number of cases that is non-negligible for practical design purposes the strength is overestimated.

Finally, focusing attention on the sole $L C C_{M}^{L} / L C C_{E X P}^{D E S}$ ratio, which is, in the Authors' opinion, the most consistent with the limit states design philosophy, reference can be made to Table 5. For each set of data as well as for all results grouped together, the mean, maximum and minimum values are reported with the associated standard deviation. It can be observed that only in a very limited number of cases, the DSM is on the unsafe side: otherwise it underestimates on average quite moderately the experimental design values, up to of $22 \%$. As far as the other EU approaches, only the 1-3 approach seems of interest for practical design purposes, despite the fact that for few families, the design experimental value of the strength is however overestimated, up to $25 \%$.

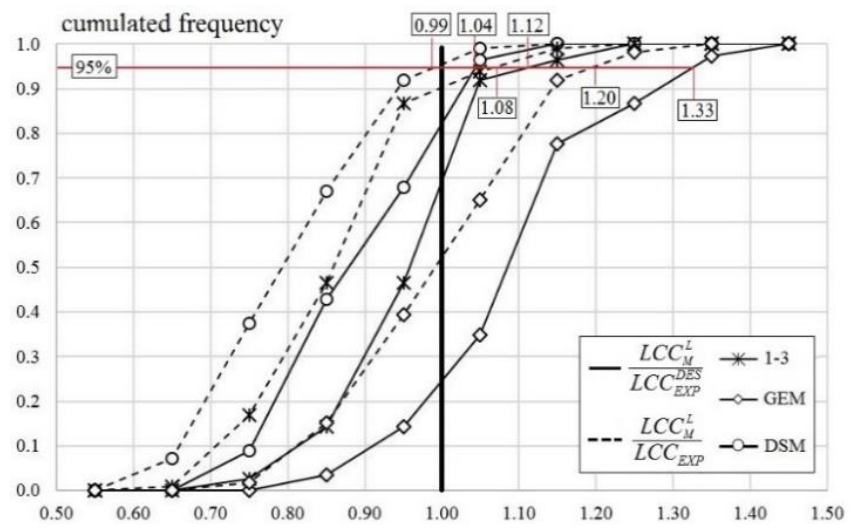

Fig. 17 Cumulative density function of the $\mathrm{LCC}_{\mathrm{M}}^{\mathrm{L}} / \mathrm{LCC}_{\mathrm{EXP}}^{\mathrm{DES}}$ and $\mathrm{LCC}_{\mathrm{M}}^{\mathrm{L}} / \mathrm{LCC}_{\mathrm{EXP}}$ ratios

\section{Concluding remarks}

Alternative approaches can be adopted to design TWCF steel beamcolumns according to the EU and US standard codes and, in the present paper, 7 different alternatives have been considered discussing their similarities and differences. The design domains, which have been proposed in terms of relationships between axial and flexural resistances along the symmetry axis, are significantly different from each other, reflecting, from the practical point of view, in different values of the load carrying capacity, or, equivalently, in non-comparable degrees of competitiveness of the members on the market. Owing to the interest in investigating the actual degree of safety of these alternatives, the axial resistance of compressed members has been evaluated, for which the data related to experimental results are available in literature. In particular, attention has been focused on experimental studies which comprised tests on three or more nominally equal specimens, in order to allow for a statistical evaluation of the experimental load carrying capacity. A direct comparison between the predicted values and the experimental one (expressed by the ratio $L C C_{M}^{L} / L C C_{E X P}$ ) attests that, especially the methods requiring the assessment of the effective width are unsafe. By considering the design experimental resistance obtained via a statistical treatments of test data, the value of the $L C C_{M}^{L} / L C C_{E X P}^{D E S}$ ratio increases, becoming significantly greater than 1, also for the DSM approach, which however is the most conservative.

As a further activity [55], the Authors also intend to extend this study to a small family test in order to calibrate a suitable safety factor to be adopted in routine design in addition to those already recommended.

Table 5

Values of the $L C C_{M}^{L} / L C C_{E X P}^{D E S}$

\begin{tabular}{|c|c|c|c|c|c|c|c|}
\hline $\begin{array}{l}\text { Cross-section } \\
\text { (spec. number) }\end{array}$ & & $\frac{L C C_{1-3}^{E U}}{L C C_{E X P}^{D E S}}$ & $\frac{L C C_{G E M}^{E U}}{L C C_{E X P S}^{D E S}}$ & $\frac{L C C_{E N V}^{E U N}}{L C C_{E X P}^{D E S}}$ & $\frac{L C C_{1-1 A}^{E U}}{L C C_{E X P}^{D E S}}$ & $\frac{L C C_{1-1 B}^{E U}}{L C C_{E X P}^{D E S}}$ & $\frac{L C C_{D S M}^{U S}}{L C C_{E X P}^{D E S}}$ \\
\hline \multirow{4}{*}{$\begin{array}{l}9 \text { lipped channels } \\
\text { [49] }\end{array}$} & mean & 0.96 & 1.23 & 1.01 & 1.02 & 1.01 & 0.97 \\
\hline & dev. & 0.0999 & 0.1535 & 0.0712 & 0.0658 & 0.0690 & 0.0169 \\
\hline & $\operatorname{Max}$ & 1.05 & 1.38 & 1.06 & 1.07 & 1.07 & 1.00 \\
\hline & $\min$ & 0.83 & 1.03 & 0.91 & 0.93 & 0.92 & 0.96 \\
\hline \multirow{4}{*}{$\begin{array}{c}3 \text { plain channel } \\
{[50,51]}\end{array}$} & mean & 0.71 & 0.84 & 0.74 & 0.77 & 0.76 & 0.78 \\
\hline & dev. & 0.0026 & 0.0115 & 0.0034 & 0.0037 & 0.0034 & 0.0031 \\
\hline & $\operatorname{Max}$ & 0.72 & 0.85 & 0.74 & 0.78 & 0.76 & 0.78 \\
\hline & $\min$ & 0.71 & 0.83 & 0.74 & 0.77 & 0.76 & 0.77 \\
\hline \multirow{4}{*}{$\begin{array}{c}4 \text { lipped channel } \\
{[50,51]}\end{array}$} & mean & 1.20 & 1.32 & 1.24 & 1.25 & 1.24 & 1.11 \\
\hline & dev. & 0.0143 & 0.0121 & 0.0115 & 0.0107 & 0.0111 & 0.0228 \\
\hline & $\operatorname{Max}$ & 1.21 & 1.34 & 1.25 & 1.26 & 1.26 & 1.14 \\
\hline & $\min$ & 1.18 & 1.32 & 1.23 & 1.23 & 1.23 & 1.09 \\
\hline \multirow{4}{*}{$\begin{array}{l}3 \text { lipped channels } \\
\text { [52] }\end{array}$} & mean & 0.88 & 0.86 & 0.93 & 1.04 & 0.99 & 0.97 \\
\hline & dev. & 0.0064 & 0.0255 & 0.0092 & 0.0087 & 0.0088 & 0.0307 \\
\hline & $\operatorname{Max}$ & 0.89 & 0.89 & 0.94 & 1.04 & 1.00 & 1.01 \\
\hline & $\min$ & 0.87 & 0.84 & 0.92 & 1.03 & 0.98 & 0.95 \\
\hline \multirow{4}{*}{$\begin{array}{l}3 \text { lipped channels } \\
\text { [52] }\end{array}$} & mean & 0.89 & 1.11 & 0.96 & 1.06 & 1.01 & 0.94 \\
\hline & dev. & 0.0119 & 0.0011 & 0.0170 & 0.0148 & 0.0158 & 0.0063 \\
\hline & $\operatorname{Max}$ & 0.91 & 1.11 & 0.98 & 1.07 & 1.03 & 0.95 \\
\hline & $\min$ & 0.89 & 1.11 & 0.95 & 1.05 & 1.00 & 0.93 \\
\hline \multirow{4}{*}{$\begin{array}{c}30 \text { lipped channels } \\
{[53,54]} \\
\text { A/B } 100\end{array}$} & mean & 0.87 & 1.00 & 0.98 & 1.02 & 1.00 & 0.81 \\
\hline & dev. & 0.0409 & 0.0490 & 0.0533 & 0.0458 & 0.0506 & 0.0725 \\
\hline & $\operatorname{Max}$ & 0.93 & 1.07 & 1.05 & 1.09 & 1.07 & 0.96 \\
\hline & $\min$ & 0.81 & 0.93 & 0.91 & 0.96 & 0.94 & 0.74 \\
\hline \multirow{4}{*}{$\begin{array}{c}30 \text { lipped channels } \\
{[53,54]} \\
\text { A/B } 150\end{array}$} & mean & 0.96 & 1.12 & 1.10 & 1.16 & 1.12 & 0.89 \\
\hline & dev. & 0.0232 & 0.0224 & 0.0319 & 0.0247 & 0.0295 & 0.0441 \\
\hline & $\operatorname{Max}$ & 1.01 & 1.16 & 1.17 & 1.20 & 1.18 & 0.96 \\
\hline & $\min$ & 0.94 & 1.09 & 1.07 & 1.12 & 1.10 & 0.83 \\
\hline \multirow{4}{*}{$\begin{array}{c}30 \text { lipped channels } \\
\text { A/B 200 } \\
{[53,54]}\end{array}$} & mean & 1.01 & 1.14 & 1.15 & 1.21 & 1.17 & 0.88 \\
\hline & dev. & 0.0670 & 0.0986 & 0.0762 & 0.0679 & 0.0748 & 0.1199 \\
\hline & $\operatorname{Max}$ & 1.14 & 1.31 & 1.29 & 1.34 & 1.31 & 1.04 \\
\hline & $\min$ & 0.91 & 0.99 & 1.04 & 1.11 & 1.05 & 0.73 \\
\hline 112 tests: & mean & 0.94 & 1.08 & 1.01 & 1.06 & 1.04 & 0.92 \\
\hline \multirow{3}{*}{$\begin{array}{l}109 \text { lipped chan- } \\
\text { nels }+ \\
3 \text { plain channels }\end{array}$} & dev. & 0.1389 & 0.1688 & 0.1528 & 0.1465 & 0.1465 & 0.1049 \\
\hline & $\operatorname{Max}$ & 1.21 & 1.38 & 1.29 & 1.34 & 1.31 & 1.14 \\
\hline & $\min$ & 0.71 & 0.83 & 0.74 & 0.77 & 0.76 & 0.73 \\
\hline
\end{tabular}

Appendix A: List of symbols

\section{Latin upper case letters}

$$
\begin{aligned}
& A_{e f f}=\text { effective cross-section area. } \\
& \mathrm{B}_{\mathrm{Ed}}=\text { Bimoment } . \\
& F_{c r e}=\text { the least elastic global buckling stress. } \\
& F_{e l}=\text { elastic buckling stress. } \\
& F_{n}=\text { critical stress. } \\
& F_{y}=\text { yielding strength. } \\
& L C C_{E X P}=\text { load carrying capacity associated with the design value. } \\
& L C C_{E X P}^{D E S}=\text { load carrying capacity associated with the experimental design value. } \\
& L C C_{M}^{L}=\text { load carrying capacity associated with the } L \text {-code and the } M \text { - approach. } \\
& L_{0}=\text { member length. } \\
& M_{b y, R d}=\text { bending resistance accounting for global lateral instability. } \\
& M_{c r}=\text { elastic critical bending moment. } \\
& \mathrm{M}_{c r d}=\text { elastic critical moment for distortional buckling. } \\
& \mathrm{M}_{c r e}=\text { bending strength for global buckling. } \\
& \mathrm{M}_{c r l}=\text { elastic critical moment for local buckling. } \\
& M_{E d}, M_{y, E d}, M_{z, E d}=\text { design bending moment. } \\
& M_{y, R}, M_{z, R}=\text { bending resistance along } y \text { or } z-\text { axis. } \\
& \mathrm{M}_{n e}=\text { overall buckling resistance for bending. } \\
& \mathrm{M}_{n}, \mathrm{M}_{n x}, \mathrm{M}_{n y}=\text { nominal bending resistance. } \\
& \mathrm{M}_{n d}=\text { bending strength for distortional buckling. } \\
& \mathrm{M}_{n l}=\text { bending strength for local buckling. } \\
& M_{y}=\text { yield moment. } \\
& M_{z, R d}=\text { bending resistance along z-axis. } \\
& N, N_{E d}=\text { member axial load. } \\
& N_{b, R d}=\text { axial stability resistance. } \\
& N_{c r}=\text { critical load for the } i \text {-member. } \\
& N_{R}=\text { axial resistance. } \\
& P=\text { required axial strength. } \\
& P_{c r d}=\text { elastic critical load for distortional buckling. } \\
& P_{c r e}=\text { overall critical load. } \\
& P_{c r l}=\text { elastic critical load for local buckling. } \\
& P_{n}=\text { nominal compression member capacity. } \\
& P_{n d}=\text { distortional buckling resistance. } \\
& P_{n e}=\text { overall buckling resistance for compression. } \\
& P_{n l}=\text { local buckling resistance. } \\
& P_{y}=\text { squash load. } \\
& R_{i}=i-t h \text { experimental results. }
\end{aligned}
$$



$R_{k}=$ characteristic value
$R_{m}=$ mean value of the family results.
$S_{\text {eff },}, S_{\text {eff:y }}=$ effective section modulus.
$S I_{k}^{j}=$ safety index associated with the $j$-code and the $k$ - approach.
$S I, S I^{E U}, S I^{U S}=$ design safety index.
$S I_{K}\left(K_{E d}\right)=$ safety index associated to the generalized $K$ force.
$W_{\text {eff, }}, W_{\text {eff:y, }}, W_{\text {eff,z } z}=$ effective cross-section modulus.

Latin lower case letters

$b=$ plate width.

$b_{e}=$ effective plate width.

$c=$ dimension of the lipped.

$d_{\text {eff }}=$ distance between the effective cross-section centroid and the web.

dev. $=$ standard deviation

$d_{g}=$ distance between the gross cross-section centroid and the web

$e_{y}=$ eccentricity along y axis

$e_{z}=$ eccentricity along $\mathrm{z}$ axis

$f_{y}=$ yield stress.

$h=$ section height.

$k_{s}=$ coefficient to determine the characteristic value.

$k_{\mathrm{z}}, k_{\mathrm{y}}, k_{\mathrm{LT}}, k_{\mathrm{yy}}, k_{\mathrm{zy}}, k_{\mathrm{yz}}, k_{\mathrm{zz}}=$ bending interaction factor

Max $=$ maximum value.

mean $=$ mean value

$\min =$ minimum value

$n=$ number of tests.

$s=$ standard deviation.

$t=$ thickness.

Greek case letters

$\alpha=$ imperfection coefficient associated with the relevant stability curve.

$\alpha_{c r, o p}=$ buckling overall frame multiplier obtained via a finite element buckling analysis.

$\alpha_{e c c}=$ angle between the vertical axis and a generic straight line through the origin in the

M-N domain.

$\alpha_{u l t}=$ minimum load multiplier evaluated with reference to the most stressed cross-sec-

tion.

$\Delta M, \Delta M_{y, E d}, \Delta M_{z, E d}=$ secondary bending moment.

$\chi_{L T}=$ reduction factor due to lateral buckling.

$\chi_{\min }=$ minimum reduction factor.

$\chi_{o p}=$ buckling reduction factor referred to the overall structural system.

$\chi_{z}=$ reduction factor for the relative buckling around $\mathrm{z}$-axis.

$\gamma_{M}=$ material safety factor

$\eta_{k}=$ coefficients depending on the specimen failure mode

$\varphi_{L T}=$ value to determine the reduction factor $\chi_{L T}$

$\varphi_{\text {min }}=$ value to determine the reduction factor $\chi_{\text {min }}$

$\lambda_{\min }=$ minimum value of element relative slenderness for pure compression.

$\overline{\lambda_{d}}=$ relative slenderness related to distortional buckling.

$\overline{\lambda_{L T}}==$ relative slenderness related to lateral torsional buckling for bending moment.

$\bar{\lambda}_{l}=$ relative slenderness related to local buckling.

$\bar{\lambda}_{c}=$ relative slenderness.

$\overline{\lambda_{o p}}=$ relative slenderness of the whole structure.

$\sigma_{c r}=$ critical elastic buckling stress.

$\sigma_{w}=$ normal warping stress

$\tau_{w}=$ tangential warping stress.

\section{References}

[1] Godley M.H.R, "Design of Cold-formed Steel Members", Rhodes ed., 361-399, 1991.

[2] Accorti M., Baldassino N., Zandonini R., Scavazza F. and Rogers C.A., "Response of CFS sheathed shear walls", Structures, 7, 100-112, 2016.

[3] Dubina D., Ungureanu V. and Landolfo R., "Design of Cold-formed Steel Structures, Eurocode 3: Design of Steel Structures, Part 1-3 - Design of Cold-formed Steel Structures", 1st edition, Wiley-Blackwell, Hoboken, NJ, 654, 2012.

[4] Schafer B.W., "Local, Distortional, and Euler Buckling in Thin-walled Columns", Journal of Structural Engineering, ASCE, 128(3), 289-299, 2002.

[5] Martins A. D., Camotim D., Dinis P.B. and Young B., "Local-Distortional Interaction in Cold-formed Steel Columns: Mechanics, Testing, Numerical Simulation and Design", Structures, 4, 38-57, 2015.

[6] Torobian S., Zheng B. and Schafer B.W., "Experimental response of cold-formed steel lipped channel beam-columns", Thin Walled Structures, 89, 152-168, 2015.

[7] Dinis P.B., Camotim D. and Silvestre N., "FEM-based analysis of the localplate/distortional mode interaction in cold-formed steel lipped channel columns", Computer and Structures, 85(19-20), 1461-1474, 2007.

[8] Bernuzzi C., Cordova B. and Simoncelli M., "Unbraced steel frames design according to EC3 and AISC provisions", Journal of Constructional Steel Research, 114, 157-177, 2015.

[9] Arduino V., Bernuzzi C. and Simoncelli M., "Design rules for steel portal frames according to EC3 and AISC 360 Provisions", Structural Magazine, 203(07), 1-9, March 2016.

[10] CEN, "Eurocode 3 - Design of Steel Structures - Part 1-1: General rules and rules for buildings", European Committee for Standardization, Brussels, 91, 2005.

[11] ANSI/AISC 360-10: "Specification for Structural Steel Buildings", American Institute of
Steel Construction, 552, 2010.

[12] Winter G., "Performance of Compression plates as part of Structural members, Research, Engineering Structures Supplement", Colston Paper, vol. II, Butlerwont, London, 179-184, 1949.

[13] Winter G., "Thin walled structures-theoretical solutions and test results", Preliminary Publication, 8th Congress IABSE, New York, N.Y., 101-112, 1968.

[14] Von Karman T., Sechler E.E. and Donnel L.H., "The Strength of Thin Plates in Compression", Transactions A.S.M.E., 54, 53-57, 1932.

[15] Winter G., "Strength of Thin Steel Compression Flanges", Transactions A.S.C.E., paper n 2305, 527-576, February 1946.

[16] CEN, "Eurocode 3 - Design of Steel Structures - Part 1-3: Design of cold formed members", European Committee for Standardization, Brussels, 130, 2005.

[17] AISI S100-16, "North American specification for the design of cold-formed steel structural members", American Iron and Steel Institute, Washington, 136, 2016

[18] Timoshenko S.P. and Gere J.M., "Theory of elastic stability", 2nd ed., McGraw Hill, NewYork, 541, 1961

[19] Vlasov V.Z., "Thin walled elastic beams", 2nd ed., Israel Program for Scientific Transactions, Jerusalem, 493, 1961.

[20] Chen W.F. and Atsuta T., "Theory of Beam-Columns. Volume 2: Space behaviour and design", Mc Graw Hill, NY, 732, 1977

[21] AS 4084, "Steel Storage Racking", Australian Standards, Australia, 110, 2012

[22] The L.H., Hancock G.J. and Clarke M.J., "Analysis and design of double-sided high-rise steel pallet rack frames", Journal of Structural Engineering, 130, 1011-1021, 2004.

[23] Bernuzzi C., Gobetti A., Gabbianelli G. and Simoncelli M., "Warping Influence on the Resistance of Uprights in Steel Storage Pallet Racks", Journal of Constructional Steel Research, 101, 224-241, 2014.

[24] Bernuzzi C. and Simoncelli M. "EU and US design approaches for steel storage pallet racks with mono-symmetric cross-section uprights", Thin Walled Structures, 113, 181-204, 2017.

[25] Bernuzzi C., Gabbianelli G., Gobetti A. and Rosti A., "Beam design for steel storage racks", Journal of Constructional Steel Research, 116, 156-172, 2016.

[26] Bijlard F., Feldmann M., Naumes J. and Sedlacek G., "The "General Method" for assessing the out-of-plane stability of structural members and frames in comparison with alternative rule in EN 1993 -Eurocode 3- part 1-1", Steel Construction, 3(1), 19-33, 2010.

[27] Szalai, J., "The General Method of EN 1993-1-1", New Steel Construction, 30-31 April 2011.

[28] Papp, F., "Global stability analysis using General Method", www.consteelsoftware.com /files/sharedUploads/Pdf/General_stability_analysis.pdf, accessed in 2017.

[29] ENV 1993-1-1, "Eurocode 3 - Design of steel structures, Part 1-1: General rules and rules for building", European Committee for Standardization, 325, 1992

[30] CEN, "EN 15512, Steel static storage systems - Adjustable pallet racking systems Principles for structural design", European Committee for Standardization, 137, 2009.

[31] CEN, prEN "15512, Steel static storage systems - Adjustable pallet racking systems Principles for structural design", European Committee for Standardization, 288, 2017.

[32] Boissonnade N., Greiner R., Jaspart J.P. and Lindner J., "Rules for Member Stability in EN 1993-1-1 Background documentation and design guidelines", ECCS-European Convention for Structural Steelworks, Publication ${ }^{\circ} 119,259,2006$.

[33] Schafer B.W. and Pekoz T., "Direct strength prediction of cold-formed steel members using numerical elastic buckling solutions", Proceedings of the 14th International Specialty Conference on Cold-Formed Steel Structures, St. Louis, Missouri USA, October 15-16, 6976, 1998.

[34] Cheung Y.K., "Finite Strip Method in Structural Analysis", Pergamon Press, New York, USA, 244, 1976

[35] Baldassino N., Bontempi F. and Malerba P., "Strips and prisms of infinite lengths", Proceedings of the International Conference on Education, Practice and Promotion of Computational Methods in Engineering using Small Computers, Macau,1-3, 539-548, August 1990.

[36] Schafer B.W "CUFSM: Elastic Buckling Analysis of thin-walled members by the finite strip method". (Open Source Software), 2005. Link: www.ce.jhu.edu/bschafer/cufsm, accessed in 2017.

[37] Li Z. and Schafer B.W., „Buckling analysis of cold-formed steel members with general boundary conditions using CUFSM: conventional and constrained finite strip methods", Proceedings of the 20th International Specialty Conference on Cold-Formed Steel Structures, St. Louis, MO, November, 17-31, 2010.

[38] Thin-Wall, Centre for Advanced Structural Engineering, University of Sidney, http://www.sydney.edu.au/engineering/civil/research/case/software/\#thin-wall, accessed in 2017

[39] Brune B. and Peköz T., "Design of cold-formed steel members - Comparison of EN 1993 1-3 and Direct Strength Method", Steel Construction, 6(2), 82-94, 2013.

[40] Dubina D., "Direct strength method for buckling design of thin walled sections", Meeting of the Working group CEN TC250 SC3 WG EN 1993-1-3, Madrid, 16-17 February, 2015.

[41] Casafont M., Pastor M.M., Roure F., Bonada J. and Peköz T., "Design of Steel Storage Rack Columns via the Direct Strength Method", Journal of Structural Engineering, 139(5) 669-679, 2013.

[42] VijayaVengadesh Kumar J., "Buckling behaviour of cold-formed steel rack uprights”, $\mathrm{PhD}$ thesis Indian Institute of Technology Madras, 207, 2016.

[43] VijayaVengadesh Kumar J. and Arul Jayachandran S., "Experimental investigation and evaluation of Direct Strength Method on beam-column behavior of uprights", Thin-Walled Structures, 102, 165-179, 2016

[44] Moen C.D., "Direct strength design of cold-formed steel members with perforations", $\mathrm{PhD}$ thesis, Johns Hopkins University, 551, 2009.

[45] CEN, "EN 10025-1: Hot rolled products of structural steels. Part 2: Technical delivery conditions for non -alloy structural steel", European Committee for Standardization, Brussels, 34, 2005

[46] Chou S. M., Seah L. K. and Rhodes J., "The Accuracy of Some Codes in Predicting the Load Capacity of Cold-formed Columns", Journal of Constructional Steel Research, 37(2), 137-172, 1996.

[47] Bernuzzi C. and Rugarli P., "A Unified Approach for the Design of Columns and BeamColumns cold-formed members. Part 1: The Approach", Costruzioni Metalliche, 5, 38-47, 2009.

[48] CEN, "EN 1990 Eurocode - Basis of structural design", European Committee for Standardization, Brussels, 87, 2002.

[49] Pu Y., Godley R. M. H. R., Beale G. and Lau H.H., "Prediction of the Ultimate Capacity 
of Perforated Lipped Channels", Journal of Structural Engineering ASCE, 125(5), 510-514, 1999.

[50] Feng M., Wang Y.C. and Davies J.M., "Structural behaviour of cold-formed thin walled short steel channel columns at elevate temperature. Part 1: Experiments", Thin-Walled Structures, 41, 543-570, 2003.

[51] Feng M., Wang Y.C. and Davies J.M., "Structural behaviour of cold-formed thin walled short steel channel columns at elevate temperature. Part 2: Design calculations and numerical analysis", Thin-Walled Structures, 41, 571-594, 2003.

[52] Dos Santos E.S., Batista E.M. and Camotim D., "Experimental investigation concerning lipped channel columns undergoing local-distortional-global buckling mode interaction", Thin-Walled Structures, 4, 19-34, 2012.

[53] Baldassino N. and Zandonini R., "SteelMAX: Experimental and numerical analysis of the structural performances of members, components and subassemblies of cold-formed profile under combined action", University of Trento, Department of Civil, Environmental and Mechanical engineering, Research report, 253, 2014.

[54] Baldassino N., Torresani G. and Zandonini R., "Instability of thin walled stiffened Csections: an experimental study", in preparation for Thin-Walled Structures.

[55] Baldassino N., Bernuzzi C. and Simoncelli M., "A proposal to improve the TWCF steel member European design approaches", Proceedings of the 8th International Conference on Thin-Walled Structures (ICTWS), Lisbon, Portugal, July 24-27, paper no. 185, 2018. 